\title{
Determination of Residential Electrical Load Components In Iraqi North Region
}

\author{
Majid. S. Al-Hafidh \\ Department of Electrical Engineering \\ Mosul University, Mosul, Iraq \\ Email-el_noor2000@yahoo.com
}

\author{
Mudhafar A. Al-Nama \\ Department of Comp. Eng. Tech. \\ Al Hadbaa Univ. College, Mosul, Iraq \\ Email-mudhafaralnema@yahoo.com
}

\author{
Azher S. Al-Fahadi \\ Department of Electrical Engineering \\ Mosul University, Mosul, Iraq \\ Email:azheralfahady@yahoo.com
}

\begin{abstract}
The residential electrical load in the city of Mosul as well as in most of cities in Iraq, is the major problem for the administration of electricity distribution. Since this kind of load is increasing drastically compared with other loads such as industrial, agricultural tourism and others which are declining for the last two decades due to unstable condition of the county.

The residential electrical load components must be determined to solve the problems resulting from the significant increase in this load. This research aims to conduct a field survey to find out and identify the components of the residential electrical load ratios and qualitative change in the months of the year. The survey was conducted in the city of Mosul in northern Iraq. The results were analyzed, and a number of recommendations were given to rationalize consumption.
\end{abstract}

Keywords - Residential electrical load components, Iraqi load, Rationalization of electricity consumption, solar water heater.

components $[2,3,4]$.

The residential load component represents an

\section{INTRODUCTION}

The electrical loads represent the important base in electric power systems, where different parts of the system are designed to ensure load supply. Therefore, the study and analysis of electrical loads forecasting represent great importance to all electric power systems. As well as the way those electrical system operate to ensure continuous electrical loads supply within the required specifications quality.

Electrical loads can be divided into several categories residential, agricultural, industrial, commercial and governmental buildings. These components are varying depending on the state of the country such as the economic, political and social states. [1]. The studies in different countries aim to find the electrical load important portion in electrical power system. The knowledge of the residential component is needed for load forecasting [5]. Furthermore, these components are important in load management and smart gird operation [6].

The diversity factor in Iraq's electricity northern region has been studied in a previous research[7]. The study found that residential electrical loads have grown at high rates exceeding standard values for stable systems. The artificial neural network technology was used, in another study to guess residential electrical loads [8].

. 
components leads to the possibility of analysis and study of the appropriate ways to rationalize these components [9].

The current research aims to conduct a field survey to find the most important components of the residential electrical load. The residential electrical load was classified into five main categories lighting, house appliances, coolers, heaters and water heaters. Each category class includes a number of components. Electrical consumption values were recorded for each category class once or twice a day for the whole year. Readings and analysis results were given in the following sections.

\section{READINGS REGISTRATION}

Readings were recorded for homes distributed throughout the revival of the city of Mosul. Electrical engineers and technicians were living in these houses. They recorded the needed data. They are working at the Department of Electrical Distribution Nineveh. A special form of the components of household loads was prepared . The household loads were recorded according to a special form designed for this purpose. Calculations can be made depending on weekly or monthly basis to find the component ratio. The weekly period is too short to show the changes in load components. The monthly period is too long due to weather changes, which lead to an inaccurate load component separation. The study were carried out based on a half month period.

\section{COMPONENTS OF RESIDENTIAL ELECTRICAL LOADS}

The Iraqi electrical load is extremely affected by climate and weather conditions, especially temperature. Figure 1 shows the minimum and maximum temperatures for the days of the year. Temperatures recorded starting from April (part of the spring in Mosul). It is clear from the figure that the temperature varies greatly during the days of the year. It approaches 50 degree Celsius in Summer, while approaches zero degree Celsius in Winter. The $25^{\circ} \mathrm{C}$ temperature is the ideal situation for comfortable weather. So when temperature increases, we need to use cooling devices and when it falls, we need to use heating equipment. Electric power is currently used for heating and cooling. In addition the electrical energy is needed for water heating, lighting and completion of household appliances.

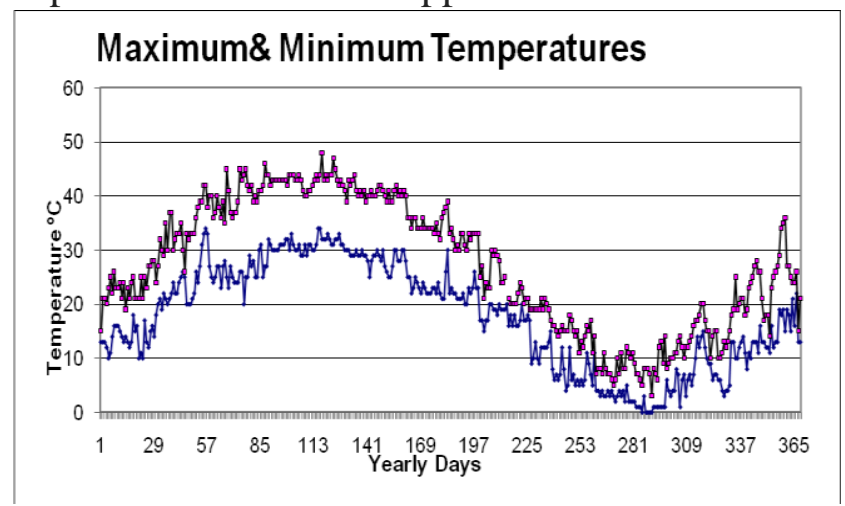

Figure 1. Maximum and minimum temperatures in Mosul city.

Figure 2 shows the lighting and home appliances components, as well as the percentage of the sum of the two components distributed on the basis of half month period for the entire year. Lighting electrical load component in figure 2 represents the smallest component followed by household appliances. The two Components are approximately constant throughout the days of the year with a limited changes during the months of the year.

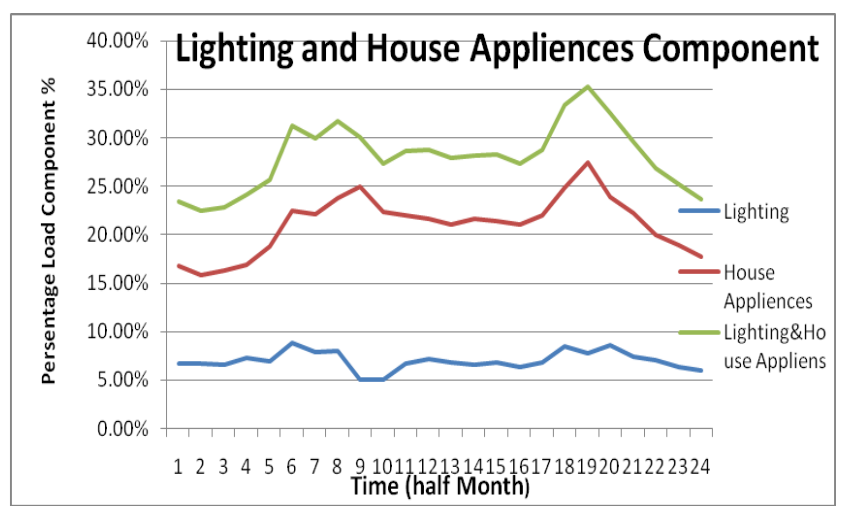

Fig. 2 Lighting and home appliances components, and their sum distributed over the months of the year. The air coolers load component represents the second component for power consumption (after lighting component) in residential electrical loads. Air heating load component ranked fourth (after the household appliances component). Figure 3 represents air cooling and heating components and their sum spread over half month 
basis of the entire year. Air cooling devices are used in summer. As well as heating devices are used in winter. The two components become less in the spring and autumn for mild temperature. The remaining portion represents electricity heaters used in cooking.

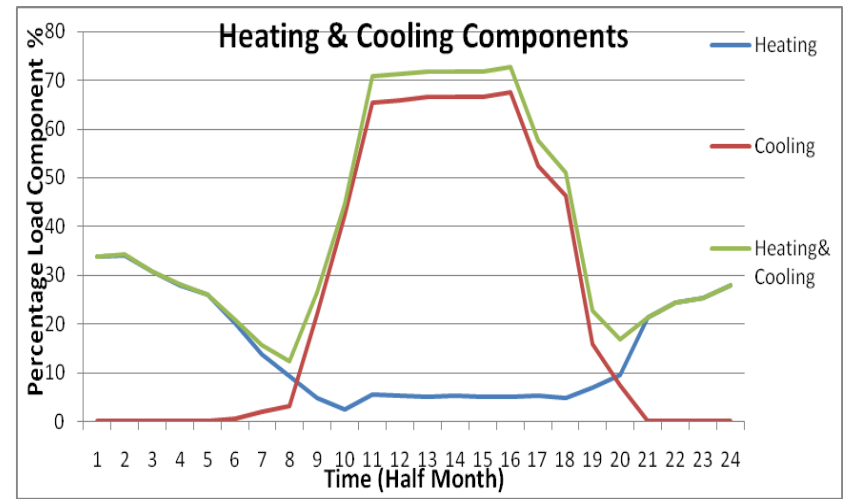

Figure 3 Air cooling and heating components and their sum spread over the months of the year.

Water heating electrical load represents the highest component of residential load components where it is used for the majority of the year. Water heating is not needed for 60-70 days in summer. Figure 4 shows the percentage of water heating component spread over half month basis of the year. The figure shows the high value of this component, which is approaching half of the total consumption for long periods of the year.

The previous figures represent detailed distribution of the average components of residential electrical load on the basis of half months of the year. Also the ratios and times of using different components during the half months of the year. The percentage use of different consumers can be different. The range between low and high consumption may be large. Table No.1 shows the percentages of the yearly low, medium, high and average of the residential electrical load component. and the consumption values.

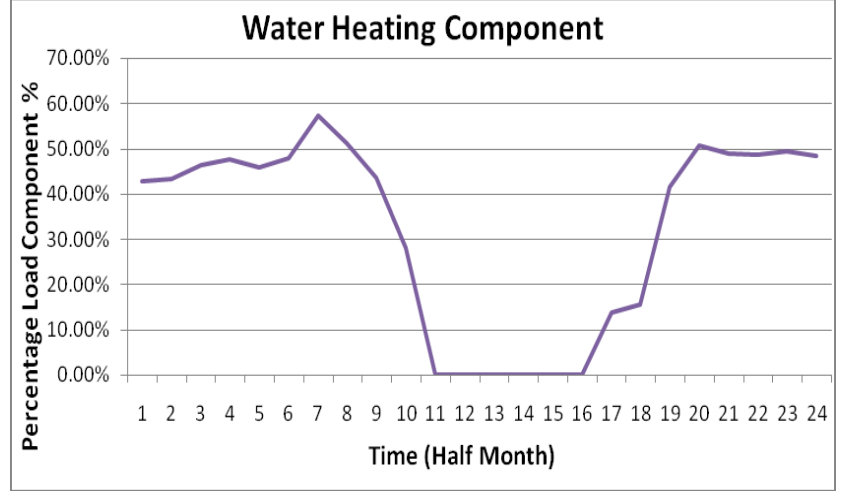

Figure 4 percentage of water heating component spread over months of the year.

Table 1 Percentage of the yearly residential electrical Load Components.

\begin{tabular}{|l|l|l|l|l|}
\hline $\begin{array}{l}\text { High } \\
\text { Consumption }\end{array}$ & $\begin{array}{l}\text { Medium } \\
\text { Consump. }\end{array}$ & $\begin{array}{l}\text { Low } \\
\text { Consump. }\end{array}$ & Average & Component \\
\hline 13.16 & 8.89 & 3.07 & 6.94 & Lighting \\
\hline 28.2 & 18.88 & 13.1 & 20.83 & $\begin{array}{l}\text { Home } \\
\text { Appliances }\end{array}$ \\
\hline 47.79 & 25.46 & 6.31 & 15.73 & $\begin{array}{l}\text { Cooling } \\
\text { Equipments }\end{array}$ \\
\hline 22.83 & 16.06 & 11.98 & 24.21 & $\begin{array}{l}\text { Heating } \\
\text { Equipments }\end{array}$ \\
\hline 60.18 & 30.4 & 13.39 & 32.29 & $\begin{array}{l}\text { Water } \\
\text { Heating }\end{array}$ \\
\hline
\end{tabular}

\section{IV.ANAL YSIS OF THE RESULTS}

Referring to the previous figures and table shown above, the analysis for the results can be abbreviated the following points:

1- Lighting component represents the lowest component of the five components $(6.94 \%))$, followed by air cooling devices component (15.73\%). While Home appliances component ranked the third (20.83\%). Air heating equipment component ranked fourth $(24.21 \%)$. Finally water heating component ranked the fifth (32.29\%).

2- Lighting and appliances components are presented along the days of the year. The sum of the two components is between 25$30 \%$ of the total residential electrical load. The sum of the two component characterized by small change with half months of the year so it can be treated as a one component when studying loads in the future. 
3- Cooling devices component represent the majority of household electrical load for summer (nearly 70\%). So the rationalization of consumption is require noting this component is mainly during summer season. Improvement of thermal insulation can result in a large reduction of this component increasing the efficiency of the residential units (contributes to improving the thermal insulation to reduce both refrigeration and heating equipment).

4- Heating component represents (30-25\%), as well as the water heating component represents (50-45\%) of the total residential electrical load for the winter. Water heating component represent the highest component in spring and autumn, due to drop of the rest of the components in these two seasons. Hot water can be supplied using solar heated.

\section{CONCLUSION AND RECOMMENDATION}

As the continuation of the previous studies, the current study illustrates another aspect of residential electrical loads, regarding the components and their distribution over the year. Loads were classified into different components. Knowing the components of the electrical load is a pillar for electrical load management efficiently and rationalizes consumption and reduces waste and address the problems of electrical load supply.

The present study represents the first step towards amendment current electricity distribution system toward smart system. The current study provides preliminary information essential to deal with the loads according to the perspective of a smart system. Therefore, the following steps are recommend:

1- Create an information base: The study provides current information base essential to deal with the loads efficiently. So the study should be expanded to include other types of electrical load (commercial, industrial, agricultural and government buildings).

2- Hot water can be supplied using solar heaters. So a practical study to find up the specifications suitable for solar heaters to meet different needs in different months of the year.

3- The sum of the two components, refrigeration and heating represent $39.94 \%$. The use of appropriate alternatives is recommended, especially for heating. As well as encourage a suitable thermal insulation building in accordance with modern requirements to ensure the reduction of heat losses. Which will leads to more efficient use of electricity in heating and cooling.

4- The sum of the two components lighting equipment and household represent $27.77 \%$. Using economic lighting equipment is recommended and household appliances to rationalization of power consumption and reduces waste.

5- The use a software-based program (HOMER) to find a combination of renewable energies to feed the household loads to reach zero energy consumption houses.

\section{Acknowledgment}

The researchers express their deep gratitude and thanks to the administration and the engineers of the General Management for North Region Electrical Distribution for their valuable help and cooperation to conduct this study.

\section{REFERENCES}

[1] I. Badran, H. El-Zayyat, and G. Halasa "Short-Term and Medium-Term Load Forecasting for Jordan's Power System" American Journal of Applied Sciences, Vol.7, No.5, 2008, PP. 763-768.

[2] R. Effatnejad "Electrical Load Components of Iran Electrical Network" Vol.2. No.4, 2010, PP. 97-100.

[3] A.B. Haney, T. Jamasb, L.M. Platchkov and M.G. Pollitt "Demand-side management strategies and residential sector: Lessons from the international experience" Electricity Policy Research Group, University of Cambridge, Nov., 2010. 
[4] Sustainable Energy Ireland "Demand Side Management in Ireland" Jan.,2008.

[5] M.K. Nzia "End Use Based Model for Residential Model Consumption Forecasting in Nairobi Region, Kenya" M.Sc. Dissertation, University of Nairobi, Kenya, 2009.

[6] R. Sharifi, S.H. Fathi and V. Vahidinasab "Customer baseline load models for residential sector in a smart-grid environment" Elsevier, Energy Report, Vol.2, PP 74-81, 2016.

[7] Majid S. Al-Hafidh, Mudhaffar A. Al-Nemma and Azher S. Al-Fahadi, "Estimation of the Diversity Factor for the Iraqi Distribution System Using Intelligent Methods". ALRafidain Engineering, Mosul, Iraq, Vol. 17, No.1, 2009.

[8] Majid S. Al-Hafidh, and Monim A. Gasim "Application of Artificial Neural Networks in Mid-Term Load forecasting for Residential Sector in Mosul City-Iraq". The Second Engineering Conference, Mosul - Iraq, 19-21 Nov, 2013.

[9] H.R.M.L. Pombeiro "Demand Side Management Strategies for the Residential Sector" M. Sc. Dissertation, University of Tecnica de Lisboa, Portugal, Oct., 2011. 